\title{
Benefits of a student-led astronomy club: lessons to inform instructional design
}

\author{
Daniel F. Barringer, Alice Olmstead, and Audiel Maldonado \\ Department of Physics, Texas State University, 749 N. Comanche St., San Marcos, TX, 78666
}

There are currently few education research footholds to help instructors build on the strengths and interests of physical science majors when teaching astronomy courses. In this paper, we describe what we learned from interviews with members of the Astronomy Club at Texas State University. We conducted and analyzed interviews with eight students that focused on their interest in astronomy and participation in astronomy-related activities at Texas State. We focus on Club activities and how students benefit from their participation in those activities to identify what is culturally relevant to our student body. We find that students experience enjoyment, feel a sense of community, and develop professional skills through their participation in the Astronomy Club. We describe how this work was motivated by and ties in to a larger pedagogical framework of culturally relevant instruction, and consider how these results can inform the design of astrophysics courses. 


\section{Introduction}

Research-based, active learning strategies in undergraduate physics and other STEM disciplines have been repeatedly shown to generate more conceptual learning and higher pass rates for students than traditional instruction [1, 2]. However, we cannot and should not holistically claim that use of research-based instructional strategies always leads to more equitable student outcomes. PER studies that interrogate the meaning and extent of equity in student outcomes reveal that this is not the case (e.g., [3-5]).

One path towards creating more equitable undergraduate physics instruction is to focus on the core ideas of culturally relevant instruction [6-10]. Culturally relevant pedagogy "teaches to and through the strengths of ethnically diverse students" (Ref. [6], p. 29). Most PER strategies partly align with culturally relevant instruction in that they start to break down power structures inherent in traditional lecture [8, 11], but they also position instructors as highly in control [11]. This is particularly problematic because PER overall has focused on students who are whiter, wealthier, and more mathematically prepared than the average physics student [12]. Our instructional strategies thus tend to be tailored to privileged white students. Compounding this problem, our natural tendency as instructors and curriculum developers is to draw on own experiences $[13,14]$, and physics instructors are predominantly white [15]. Thus, we often impose dominant disciplinary ideas and practices onto underrepresented minority (URM) students rather than teaching to their strengths.

Listening to and partnering with students, especially URM students, is essential in culturally relevant instruction. While PER as a field does not yet reflect this ideal well, many members of the PER community have been engaging in work that pushes us in this direction. For example, Sabella et al. [16] have drawn on tools of culturally relevant instruction to foster collaborative instructional partnerships between students and faculty. Their approach combines the Learning Assistant model [17] with Emdin's idea of co-generative dialogues [9], or structured exchanges between teachers and small groups of students to help bridge cultural divides and identify better instructional approaches for those students. Similarly, Quan et al. [18] have been engaging URM students as partners in designing supports for undergraduate STEM students through the Access Network initiative.

Our current work centers on developing new astrophysics courses that are culturally relevant for Texas State University students, and distilling lessons for the Physics and Astronomy Education Research community. Texas State University is a large, diverse Hispanic Serving Institution in central Texas, which can help us to avoid some of the demographic limitations of past PER studies [12]. In 2018, the undergraduate student body was $53 \%$ racial or ethnic minorities, including 37\% Hispanic and 11\% African American students. The College of Science and Engineering reflects these same demographics (39\% Hispanic, 11\% African American in 2018). Texas State also includes a high proportion of low-income students, with $37 \%$ receiving Pell Grants in 2017 [19].

Astrophysics courses for physical science majors present an opportunity to design instruction with these students from a nearly blank slate. The 2017-2023 Department of Physics strategic plan includes disciplinary expansion into astrophysics, including hiring new faculty and creating new upper-division courses. This strategic direction was driven by student requests. Moreover, almost no research on upperdivision astrophysics courses exists in the literature. Instead, most astrophysics courses are structured and taught based on the consensus ideas of professional astrophysicists [20], and innovative astrophysics courses have not been studied. By documenting our local efforts to design astrophysics courses for and with Texas State students, we aim to help address this gap in a way that is tailored to a diverse student population.

Our efforts to design new astrophysics courses include multiple mechanisms for white faculty (including the first two authors) to listen to and partner with students, and thus bridge cultural divides. These mechanisms include holding open planning meetings with faculty and students, engaging students in research analysis and course design over sustained periods (including the third author), and learning about the undergraduate astronomy club through attending club meetings and interviewing students. In this paper, we focus on what we have learned from the Texas State Astronomy Club. We address the research question: What activities do undergraduate STEM students participate in through a student-led astronomy club, and how do they benefit from those activities?

\section{Literature review}

There is a long history of researching informal learning environments using a variety of theoretical tools [21]. We draw on two overlapping bodies of literature in our study: communities of practice [22, 23] and affinity spaces [24].

Practices serve as "the source of coherence for a community" ([23] p. 72); they are the means by which novices steadily achieve centrality within a community through legitimate peripheral participation [22]. Novices adopt and contribute to the social values of the community, affecting their own respective identities and the larger collective identity of the community [23]. Teaching roles are fluid within a community of practice, with different members taking on different roles according to their own levels of expertise in a particular area. Azevedo [25] observed this fluidity in a study of amateur astronomy clubs, in which newcomers to the community were not new to particular practices of astronomy and were able to teach older members in certain areas, while still being novices in others.

An affinity space is a setting in which people interact because of a common interest. Affinity spaces are defined by this common interest, and not all members of affinity spaces necessarily consider themselves to be part of a community [24]. The reason we consider the affinity space framing is because, in a setting where many distinct activities take place, 
it is often easier to consider membership as not depending on strength in particular practices but rather on organizing around a shared interest. In an affinity space, newcomers are not assumed to be novices to the practices of the community, just the space itself [24]. Participation in the activities of the affinity space then is the chief determinant of the centrality of one's membership. In an affinity space, different members seek different kinds of mastery and to different extents. While Azevedo [25] did not explicitly use an affinity space framing in their study of amateur astronomy groups, we notice that he observed this phenomenon of multiple paths towards centrality within the groups he studied.

Drawing on the community of practice and affinity space frameworks allows us to more completely describe two intertwined yet distinct aspects of individuals' participation in informal educational settings: engagement with a community of practitioners and engagement with the topic around which the community is organized. Studying interest-driven practices in informal settings can inform the development of formal science learning environments that legitimately build on and expand learners' interests [25]. When designing for equity, the practices of informal science communities can and should inform the values of school-based learning [26]. When specifically applied to communities in which URM students participate, these practices and values can form the core of culturally relevant instruction.

\section{Methods}

We conducted semi-structured interviews with eight student members of the Astronomy Club. During the interviews, students were asked about their general interest in astronomy and their participation in astronomy-related activities at Texas State including, but not limited to, their Club-related activities. Demographic information and student pseudonyms are summarized in Table I.

In this paper, we focus on students' experiences within the Astronomy Club. This focus gives us the opportunity to explore how students collectively engage with astronomy in a space they control. Drawing from the theoretical frameworks of communities of practice and affinity spaces, we coded these data for three emergent themes: enjoyment, sense of community, and developing professional skills. In coding for professional skills, we noted individual students' career interests and foregrounded skills that aligned with those interests. The codes were broad enough to capture the primary features of both theoretical frameworks. The codes also aligned with the initial observations of commonalities across interviews made by the two first authors and participant "Amber." All authors discussed and iteratively refined their understanding of the codes, with the first and third authors coding all eight of the interviews independently.

Our analysis also involved identifying Club practices and origins from students' perspectives. We specifically investigated the Astronomy Club's origins in order to assess the degree to which the Astronomy Club practices are authentic to the student community. Philips and Azevedo [26] point out that settings of everyday science learning are not independent of the broader sociocultural context in which they exist. As such, we cannot assume that students' expressions of themselves are fully reflected in a particular setting. Moreover, faculty (the club advisor and the two first authors) routinely participate in the Astronomy Club, which could further shape how students express themselves. However, learning from the culture and practices that students negotiate within a community that they play a significant role in constructing can bring us closer to understanding students' strengths and interests.

The two first authors also participated in Club meetings and events over the past academic year. Neither of us serves as Club advisor, and we were not involved in initiating or planning outreach events. During meetings, we shared news items or provided additional background information on news the students discussed, and have brought in outside speakers to present to the Club. We draw on these experiences and our sustained relationships with study participants to help contextualize and frame students' accounts.

\section{Results}

\section{A. Astronomy Club origins and activities}

The Physics Department hired a new astronomy-focused professor and observatory manager for Fall 2016. The founding Club members we interviewed-Amber, Olivia, Travis, and Jimmy-describe his hire as a catalyst for the Club formation. Amber recalls the nature of the initial pre-Club meetings:

It was just a couple people that met up on the roof with [the new astronomy professor] his first year. We were just like, "Hello. We all love astronomy." We had pondered about making a Club. We were like, "I wonder if there would be enough people interested in it?" We sat there for like a year, and we were like, "Okay, next year we're gonna do it." Then we held elections and that next year we had Astronomy Club.

Olivia describes creating demonstrations, planning outreach events, and growing the Club in its first years:

When we first started, it was mainly activities together. We were planning the planetarium, we were planning projects like the gravity well. Every meeting was just about ideas on where to show our projects to, which schools to go to, what events there are, how to do community service. It was a lot about how to start the Club, how to get it going and get more members.

Amber notes a strong focus on outreach within the Club, stating "Astronomy Club is really outreach I'd say, at this point." Other members draw attention to additional Club activities such as using the campus observatory, discussing astronomy news, and engaging with guest speakers at Club meetings.

Travis, the first Club president, reflects on how the Club has evolved and its current state within the university: 


\begin{tabular}{lllll}
\hline \hline Pseudonym & Race/Ethnicity & Major & Role in Club & Career interests \\
\hline Travis & Hispanic/Latinx & Physics & $\begin{array}{l}\text { Founding member; 1st president; } \\
\text { outgoing treasurer }\end{array}$ \\
Amber & White/uncertain & Physics & $\begin{array}{l}\text { Founding member; outgoing VP; } \\
\text { incoming president }\end{array}$ & Observatory director \\
Connor & White & Physics & Incoming treasurer & Physics/astronomy professor \\
Jimmy & White & Computer science & Founding member & Programmer, particularly of telescopes \\
Olivia & Hispanic/Latinx \& white & Biology & Secretary & Biologist \\
Erin & White & Biology & Outgoing president & Peace Corps; uncertain \\
Robyn & White & Electrical engineering & Incoming VP & NASA Engineer \\
Josh & White & Physics & New member & Uncertain, maybe grad school \\
\hline \hline
\end{tabular}

TABLE I. Pseudonyms and characteristics of students in the study. All students identify within the gender binary; their pseudonyms reflect the most common gender associated with that name.

At first, we were just a rag tag team of students. It was just random people thrown together to make the Club happen. Now it's a club with a focus, it's a club with a direction, it's a club with dedicated people in it to help maintain that focus. It's forming into a formidable club. I see this as a permanent feature of Texas State.

\section{B. Benefits of Astronomy Club activities}

In the following sections, we elaborate on the benefits Club members perceive from participating in specific Club activities and in the Club generally.

\section{Enjoyment}

Every student we interviewed enthusiastically expressed how much they enjoy participating in the Astronomy Club. Some students emphasize enjoying the community aspects of the Club. For example, Olivia describes her enjoyment of socializing at stargazing events:

We bring some telescopes out to Reimer's Ranch and we all just get together, put some chairs around, bring food and we look through telescopes, stargaze and just spend quality time with each other.

Josh, a newcomer to the Club, also considers community as he talks about his positive first impressions of the Club:

I like the community already, they're really funny, and inviting. ... Just being in a space-I guess this is part of the community-being in a space where everybody has the same, almost specific interests is really inspiring, I suppose. That's probably honestly my favorite part.

In the quote above, Josh also describes how his enjoyment stems from his interest in the subject matter. Other members similarly foreground this aspect of enjoyment, often framed around sharing their interest with others. Jimmy enjoys assessing his own understanding of astronomy through outreach:

For me, [outreach is] why the Club is so fun. I get to find out how I'm doing in real time if I'm teaching or if I'm talking with somebody.

Robyn enjoys outreach as well, in this case, because she is enthusiastic about lasers:

I work with lasers and I like the science behind lasers. I do that laser simulation regarding sound and light and how they interact and everything, which is super cool.

Thus we see students deriving enjoyment from the Club in a variety of ways.

\section{Sense of community}

All students describe the importance of the sense of community they experience as members of the Club. Some students specifically describe how having shared interests with other Club members leads to this sense of community. For example, Robyn describes how she is able to freely express her interest in astronomy within the Club, and how that creates a sense of connection with other members:

I think because I'm secretly a nerd and they're totally secretly nerds, too. It's like we're all there for one reason, right? We all like astronomy. That's definitely a bond that we can have together and talk about and talk new things.

Jimmy also finds that discussing astronomy with other Club members is important for his sense of belonging:

One of the reasons why I'm much more invested in the Astronomy Club is because I'm surrounded by people who are willing to engage in discussion with me about the subject. ... [it] makes me feel very involved. 
Erin was a biology major who did not have existing relationships with any of the Club members before joining. She describes herself as "really anti-organization when I came to college." However, she quickly found herself experiencing a sense of belonging within the Club. Her level of involvement "snowballed," and she eventually became Club president. She describes how much the relationships she developed through the Club and the Club itself mean to her now:

I made friends in the Club and I was like, "Oh, this would be a hard organization to leave."

Connor, a physics major and relatively new member, envisions himself becoming a more central to the community because of the way he is treated by other Club members:

I believe the people though were very warm and welcoming and inviting ... I find sometimes personally some people in STEM might not be as inviting, if that's a good way of putting it. And that's something I did not find with the Astronomy Club. Everyone wanted to learn your name, wanted you to come and really they just were excited about space and they're excited if anyone else was excited about space.

These data suggest that the Club provides a sense of community to members that increases their desire to participate and remain involved.

\section{Developing professional skills}

By engaging in the community practices of the Astronomy Club, students also gain professional skills related to leadership, teaching, information-seeking, engaging in professional discourse, and engineering.

Like Erin, Travis describes his participation in the Astronomy Club as "the first time I was really involved in an organization." He reflects on how being the first Club president taught him about leadership and his own interests:

Sometimes ... being president isn't all that fun, but, I mean, it was fun. It was just the work that goes into making it what it is, and that's where I learned more about myself, that I do like speaking in front of people, I do like speaking about what I like in front of people. I do like talking about astronomy in front of people, and that's where that seed of "I wanna educate people about astronomy" came from.

Several other members of the Club also express developing their interest and/or skill in teaching as a result of participating in Club activities. For example, Jimmy describes the Astronomy Club as "a great avenue...to practice any kind of teaching," while Connor describes "being on the borderline of becoming, or wanting to become an educator in STEM" as a result of participating in outreach activities.

Connor talks about how he develops content knowledge through reading and discussing astronomy news:

I like talking about the news and getting other people's opinions and also information. I'm not that informed or higher up in my education, so it's nice to listen to other people who have read the same article as me, but have different backgrounds or different information that they could add to it.

We see Connor's ability to engage in these discussions as an important professional skill that he is likely developing. Similarly, we see Erin describing information-seeking skills that could be valuable to her in many professional settings:

There were some questions I didn't even know to ask until I joined Astronomy Club. And while I don't always find the answers in the Astronomy Club, I'll learn something or I'll hear something and be like, "I don't know what that is." And then I have to go do research outside and figure it out.

Some students explicitly connect technical skills they are developing through their involvement in the Club to their career goals. For example, Amber describes the value she places in working with telescopes:

Another thing that we did is we realized that we need to fix the telescope, and so I have a fellowship now to motorize the 16-inch upstairs on the fourth story. So I'm fixing the observatory here. That's a pretty big accomplishment for me, I'd say, 'cause that's what I want to be here for.

\section{Conclusions}

We identified multiple student activities and interests that occur in a student-led and -organized space at Texas State (the Astronomy Club) that could serve as starting points for culturally relevant instructional design. We find that students experience enjoyment, feel a sense of community, and develop professional skills through their participation in a studentdriven astronomy club. These benefits were broadly derived from positive interactions with other Club members and Club activities such as leading and organizing outreach events, public observing nights, sharing and discussing astronomy news, and engaging with guest speakers. Students specifically develop skills related to teaching, leadership, knowledge seeking, building and designing demonstrations, and repairing telescopes. In many cases, these skills seem to feed directly into students' career plans.

We posit that students' interests and lived experiences are reflected in their engagement with astronomy through the Astronomy Club. Because of this, course design that attempts to mirror the practices and implicit goals that students pursue through the Astronomy Club could lead to more culturally relevant instruction. Creating a formal course based on this analysis could provide opportunities to explore the extent to which the perspectives of the students initially interviewed are representative of physical science majors at Texas State. Continuing to foreground and learn from students' experiences and authentic practices during course design could lead to more equitable outcomes in physics and astronomy. 
[1] S. Freeman, S. L. Eddy, M. McDonough, M. K. Smith, N. Okoroafor, H. Jordt, M. P. Wenderoth. Active learning increases student performance in science, engineering, and mathematics. Proceedings of the National Academy of Sciences of the United States of America 111, 8410 (2014).

[2] S. R. Singer, N. R. Nielsen, H. A. Schweingruber, and others. Discipline-based education research: understanding and improving learning in undergraduate science and engineering (National Academies Press, 2012).

[3] I. Rodriguez, E. Brewe, V. Sawtelle, L. H. Kramer. How gender and reformed introductory physics impacts student success in advanced physics courses and continuation in the physics major. Physical Review Special Topics - Physics Education Research 8, 020103 (2012).

[4] E. Brewe, V. Sawtelle, L. H. Kramer, G. E. O'Brien, I. Rodriguez, P. Pamela. Toward equity through participation in Modeling Instruction in introductory university physics Physical Review Special Topics - Physics Education Research 6, 010106 (2010).

[5] L. Kost, S. Pollock, N. Finkelstein. Characterizing the gender gap in introductory physics. Physical Review Special Topics Physics Education Research 5, 1 (2009).

[6] G. Gay, Culturally responsive teaching: Theory research, and practice (Teachers College Press, New York, NY, 2000).

[7] S. Brown-Jeffy and J. E. Cooper. Toward a Conceptual Framework of Culturally Relevant Pedagogy: An Overview of the Conceptual and Theoretical Literature. Teacher Education Quarterly, 65 (2011).

[8] E. Tan and A. C. Barton. Designing for rightful presence in STEM-rich making. Proceedings of the 7th Annual Conference on Creativity and Fabrication in Education - FabLearn '17, 1 (2017).

[9] C. Emdin, For white folks who teach in the hood... and the rest of y'all too: Reality pedagogy and urban education (BeaconPress, Boston, MA, 2016).

[10] G. Ladson-Billings. Culturally Relevant Pedagogy 2.0: a.k.a. the Remix. Harvard Educational Review 84, 74 (2015).

[11] M. Dancy and C. Henderson. Framework for articulating instructional practices and conceptions. Physical Review Special Topics- Physics Education Research 3, 010103 (2007).

[12] S. Kanim and X. C. Cid. The demographics of physics education research.

[13] D. C. Lortie and D. Clement, Schoolteacher: A sociological study (University of Chicago Press, Chicago, 1975).

[14] A. Oleson and M. T. Hora. Teaching the way they were taught? Revisiting the sources of teaching knowledge and the role of prior experience in shaping faculty teaching practices. Higher
Education 68, 29 (2014).

[15] R. Ivie, G. Anderson, S. White. African Americans Hispanics among Physics Astronomy Faculty: Results from the 2012 Survey of Physics \& Astronomy Degree-Granting Departments (AIP Statistical Research Center, College Park, 2014)

[16] M. S. Sabella and A. G. Van Duzor, F. Davenport. Leveraging the expertise of the urban STEM student in developing an effective LA Program: LA and Instructor Partnerships. 2016 Physics Education Research Conference Proceedings, 288 (2016).

[17] V. Otero, S. Pollock, N. Finkelstein. A physics department's role in preparing physics teachers: The Colorado learning assistant model. American Journal of Physics 78, 11 (2010).

[18] G. M. Quan, B. Gutmann, J. C. Corbo, B. Pollard, C. A. Turpen, and The Access Network. The Access Network: Cultivating Equity and Student Leadership in STEM, 2019 PERC Proceedings (under review).

[19] Distribution of Federal Pell Grant Program Funds by Institution. Retrieved 7/1/2019. https://www2.ed.gov/finaid/prof/resources/data/pellinstitution.html

[20] J. E. Cabanela and R. B. Partridge. So What IS the Astronomy Major?. Astronomy Education Review 1, 67 (2002).

[21] National Research Council. Learning Science in Informal Environments: People, Places, and Pursuits. Committee on Learning Science in Informal Environments. Philip Bell, Bruce Lewenstein, Andrew W. Shouse, and Michael A. Feder, Editors. Board on Science Education, Center for Education. Division of Behavioral and Social Sciences and Education. (The National Academies Press, Washington, DC, 2009).

[22] J. Lave and E. Wenger, Situated Learning: Legitimate Peripheral Participation (Cambridge University Press, Cambridge, England, 1991).

[23] E. Wenger, Communities of Practice: Learning, Meaning, and Identity (Cambridge University Press, Cambridge, England, 1998).

[24] J. P. Gee. 6: Affinity Spaces. In Situated Language and Learning: A Critique of Traditional Schooling. (Routledge, Abingdon, England, 2004).

[25] F. Azevedo. The Tailored Practice of Hobbies and Its Implication for the Design of Interest-Driven Learning Environments. Journal of the Learning Sciences, 22, 3 (2013).

[26] T. Philips, F. Azevedo. Everyday science learning and equity: Mapping the contested terrain. Science Education 101, 4 (2017). 